\title{
Sirtuin-1 mediates the obesity induced risk of common degenerative diseases: Alzheimer's disease, coronary artery disease and Type 2 diabetes
}

\author{
Ian James Martins ${ }^{1,2^{\star}}$, Andrea. C. Wilson ${ }^{1,2}$, Wei Ling Florence Lim $^{1,2}$, Simon. M. Laws ${ }^{1,2,3}$, \\ Stephanie. J. Fuller ${ }^{3}$, Ralph Nigel Martins ${ }^{1,2,3}$ \\ ${ }^{1}$ Centre of Excellence in Alzheimer's Disease Research and Care School of Medical Sciences, Edith Cowan University, Perth, Aus- \\ tralia; ${ }^{*}$ Corresponding Author: i.martins@ecu.edu.au \\ ${ }^{2}$ School of Psychiatry and Clinical Neurosciences, The University of Western Australia, Perth, Australia \\ ${ }^{3}$ McCusker Alzheimer's Research Foundation, Hollywood Medical Centre, Perth, Australia
}

Received 16 November 2012; revised 20 December 2012; accepted 26 December 2012

\begin{abstract}
Obesity, especially at mid-life, is a major risk factor for atherosclerosis, insulin resistance and the metabolic syndrome, which in turn contribute to coronary artery disease (CAD), Type 2 diabetes and Alzheimer's disease (AD). The rise in overweight and obesity in all societies is prompting intense research into the causes and effects of the condition. Obesity disrupts many body systems including glucose and lipid metabolism, circadian rhythms and liver function. It also causes or increases inflammation and oxidative stress. Within cells, the endoplasmic reticulum (ER) appears to be particularly susceptible to such metabolic disruption. Sirtuin 1 (Sirt1) and leptin have received attention recently as they are central regulatory factors for the body's metabolic pathways which interact at particular levels, for example lipid and Abeta metabolism. This mini-review discusses recent findings concerning obesity, lipid metabolism and the role of Sirtuin 1 and how all influence the ER. A greater understanding of obesity and its effects on metabolic control systems of the body are required, to develop pharmacological, dietary and lifestyle changes that will reduce the incidence of CAD, Type 2 diabetes and AD.
\end{abstract}

Keywords: Obesity; Sirtuin 1; Alzheimer's Disease; Cardiovascular Disease; Diabetes

\section{INTRODUCTION}

Obesity is associated with an increased risk for athero- sclerosis, contributing to the onset of coronary artery disease. Obesity is also well-known to be associated with Type 2 diabetes, insulin resistance and hyperlipoproteinemia. In fact, obesity and the metabolic syndrome have become major public health issues as they have reached epidemic proportions in Western populations [1]. Obesity is now recognized as an important risk factor for $\mathrm{AD}$ and cognitive decline [2-10]. For example, in a study of 8534 individuals from the Swedish Twin Registry, it was found that both overweight and obesity at midlife increase the risk of dementia, $\mathrm{AD}$, and vascular dementia [11,12], and in an 18 year follow up study of overweight women, a higher incidence of dementia (particularly AD) was found in these women relative to controls [13]. Obesity and overweight, as measured by body mass index and skin fold thickness, has been strongly associated with $\mathrm{AD}$ and dementia, independent of the development of diabetes and cardiovascular disorders [6].

\section{OBESITY AND ADIPOSITY}

Obesity is defined as having a body mass (BMI) index of $>30$ (BMI = weight in $\mathrm{kg} /\left[\right.$ height in $\left.\mathrm{m}^{2}\right)$, whereas overweight is defined as having a BMI from 25 to 30 . Obesity is a medical condition in which excess body fat has accumulated to such an extent that it is likely to have adverse effects on life expectancy and leads to increased health problems. Adiposity is the body fat tissue content, and as the degree of adiposity increases, the level of adiposity can be defined as being overweight or obese by measures such as the BMI.

\section{MIDLIFE OBESITY}

Being overweight or obese in early life or middle adult 
life leads to hyperinsulinemia which may lead to diabetes later in life. Therefore the timing and the development of adiposity is critical to the understanding how it is associated with the pathogenesis of AD (Figure 1).

In a recent longitudinal study of 1149 individuals, midlife obesity was found to be a significant risk factor for $\mathrm{AD}$ in later life [14]. Abnormally high levels of the Abeta peptide are believed to be involved in AD pathogenesis, and in our own recent studies, we have found a strong positive correlation between body fat and blood plasma Abeta levels in cognitively normal individuals aged between 23 to 65 [15].

\section{DIET AND RISK OF ALZHEIMER'S DISEASE}

Epidemiological studies have shown that people of similar ethnic origins yet living in different environments can have significantly different risks of dementia $[16,17]$. Nigerians living in Africa have a much lower incidence of $\mathrm{AD}$ when compared with African Americans living in the US [16]. Similar results were obtained with Japanese people living in Japan when compared with Japanese Americans living in the US [17]. These differences were believed to be mostly due to dietary differences. Diet and dietary fat intake are now considered particularly important when comparing the lifestyles of populations screened for AD [18]. In support of obesity and caloric intake influencing $\mathrm{AD}$ risk, for example, one study has found that the more saturated fat consumed in a meal the greater the risk for developing AD and senile dementia [19]. In other studies of humans and other animals, it has been found that feeding diets high in saturated fats results in learning and memory impairments. High caloric intake of saturated fat has also been associated with greater cerebral Abeta amyloid deposition [19]. In contrast diets containing chronically high levels of polyunsaturated fatty acids result in better learning when compared with diets containing saturated fat [20].

Cholesteryl esters can be hydrolysed in lysosomes following which fatty acids become available for oxidative metabolism, in particular to carbon dioxide [21]. As a result, the metabolism of dietary lipids can be assessed using a stable isotope breath test [21] and using such a test, the clearance and metabolism of cholesterol-rich dietary lipoproteins in obese individuals has been found to be markedly lower than normal, indicating that the ingested fat was poorly cleared and metabolised from the blood plasma. Obese individuals have high triglyceride levels and low HDL levels with an increase in small LDL particles $[22,23]$. In animal models of $\mathrm{AD}$, strong correlations between high fat/high cholesterol diets and increases in brain Abeta levels and HDL cholesterol levels and lower LDL cholesterol levels have been shown. For example, increased cerebral Abeta deposition as well as increased memory impairment has been shown in AD model transgenic mice fed high fat diets, and although exercise [24] and environmental enrichment [25] have been shown to reverse these effects to some extent, when translating to clinical situations, one major recommendation would always be to reduce saturated fat intake. Longitudinal studies have shown that people with an overall lower calorie intake also have a reduced incidence of AD later in life [13].

In obese individuals, there are several abnormalities in free fatty acid (FFA) metabolism [26,27]. There is an increase in FFA release from adipose tissue to the blood plasma which impairs the uptake of glucose by muscle

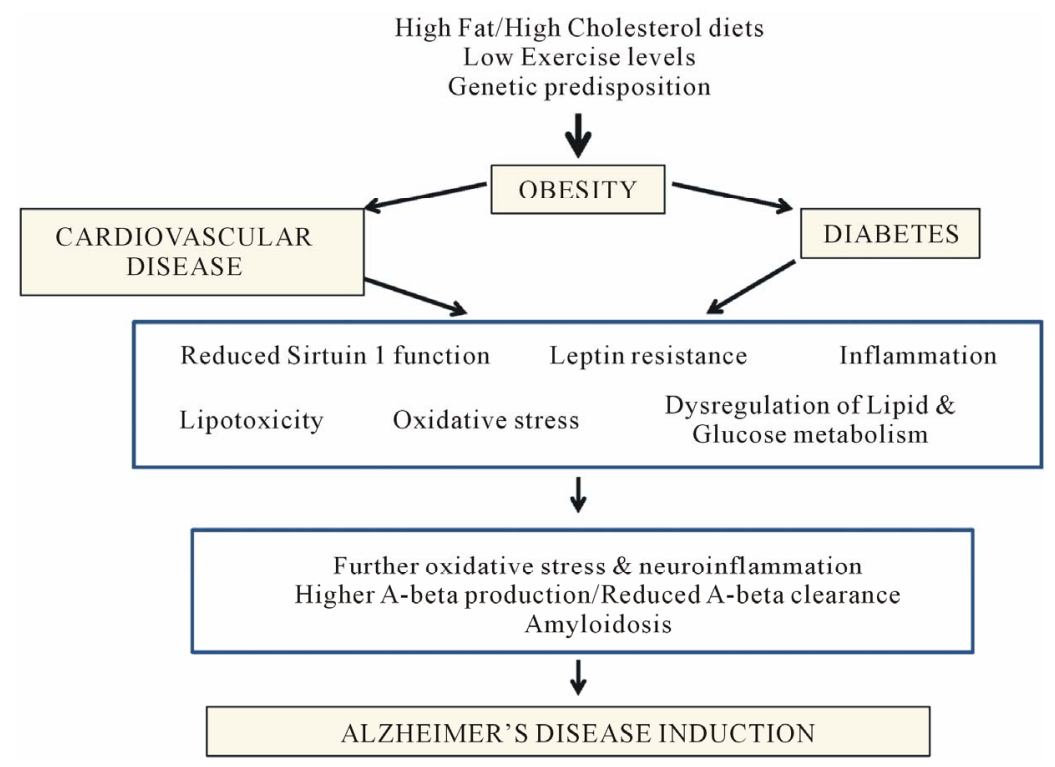

Figure 1. Obesity as a mechanism for induction of Alzheimer's disease. 
$[26,27]$. Furthermore, the rate of lipolysis is accelerated in visceral adipose tissue and the increase in circulating FFA results in dyslipidemia, hyperinsulinemia and hyperglycemia [28].

Essential fatty acids such as cis-linolenic acid (LA) and alpha-linolenic acid are essential for humans, and the metabolism of these fatty acids is altered in obesity and other diseases [29,30]. In AD individuals the composition of phospholipid fatty acids is also altered [31] with increases in saturated fatty acids (14:0, 16:0, 18:0) and decreases in polyunsaturated fatty acids being found [31]. These alterations in phospholipid fatty acid composition may be associated with the high saturated fatty acid intake at midlife in $\mathrm{AD}$ individuals [32].

\section{LEPTIN AND OBESITY}

Leptin is a $16-\mathrm{kDa}$ hormone that plays a key role in regulating energy intake and energy expenditure. It acts on the hypothalamus to influence appetite and metabolism. Leptin regulates lipid homeostasis and has also been shown, in vitro and in vivo, to have important effects on Abeta levels via apolipoprotein E-dependent pathways [33]. It is secreted by adipose tissue and levels are usually directly proportional to the levels of body fat. Therefore, obese individuals have elevated leptin levels that is related to their increased adipose tissue mass [33]. It appears that obese people are resistant to the effects of leptin, in much the same way that people with type 2 diabetes are resistant to the effects of insulin [34].

\section{INSULIN AND OBESITY}

Insulin modulates cognition and other aspects of normal brain function. The insulin resistance syndrome is characterized by chronic high levels of insulin, reduced insulin activity and reduced brain insulin levels. Insulin resistance together with obesity can lead to increases in cardiovascular risk factors such as dyslipidemia, hypertension and Type 2 diabetes [35]. Insulin resistance is also associated with age-related memory impairment and an increased risk of Alzheimer's disease. High insulin levels are known to increase the levels of Abeta and inflammatory changes that are linked to age and obesity $[35,36]$. For example, AD-model mouse studies have shown that inducing type 2 diabetes caused an increase in Abeta production and Abeta neuropathology, impaired insulin receptor signal transduction, and a significant potentiation of cognitive deterioration compared to non-diabetic control AD mice [37]. It has been suggested that the higher levels of brain Abeta in such mice may be due to result from the high insulin completely consuming insulin-degrading enzyme (IDE) activity-IDE can degrade both insulin and Abeta but has a preference for insulin thus resulting in elevated Abeta [38]. Preventing or correcting insulin abnormalities may reduce the risk of age related memory impairment and AD.

High fat diets are known to interfere with glucose tolerance and insulin sensitivity and yet such detrimental effects depend greatly on the type of fat consumed [3941]: saturated and trans-fatty acids increase insulin resistance whereas mono- and polyunsaturated fats decrease resistance and protect against the disease.

\section{SIRTUIN 1}

The sirtuin proteins, also known as silent information regulators, are class III histone deacetylases (HDAC). Sirtuin 2 was the first to be identified: it was found to be a mediator of replicative lifespan in budding yeast. It was then shown to modulate longevity in worms and flies. These protective actions are believed to result from the beneficial regulation of stress management and energy homeostasis [42-56]. Sirtuins are now known to regulate several cell functions by deacetylating both histone and non-histone targets.

The mammalian homologue, Sirtuin 1 (Sirt1), seems to have evolved complex systemic roles in cardiac function, DNA repair and genomic stability. Sirt1 has been shown to play a central role in metabolic homeostasis. It is involved in gluconeogenesis in the liver, fat mobilisation from white adipose tissue, cholesterol metabolism, insulin secretion from the pancreas and energy metabolism in general [57]. For example, Sirt1 deacetylates and activates the transcriptional co-activator PGC1-alpha and the transcription factor FoxO1 in the liver, to promote gluconeogenesis. In adipose tissue, Sirt1 triggers fat mobilisation by inhibiting peroxisome proliferator-activated receptor gamma (PPAR-gamma), and in the pancreas, Sirt1 repression of the uncoupling protein 2 (UCP2) increases insulin secretion [58]. Sirt1 also influences mitochondrial biogenesis, inflammation (cytokine release) and amyloidosis [42-56].

Calorie restriction has been shown to extend life span. In fact, it has been shown to extend the median and maximum life span of numerous organisms including yeast, flies, worms, fish, and rodents and mammals. It is now believed that this may be mediated partly due to the increase in Sirtl activity which is induced by calorie restriction. For example, increased Sirt1 activity mediates mitochondrial biogenesis, which in turn may reduce the production of reactive oxygen species, a possible cause of aging and AD pathogenesis [59]. The involvement of Sirt1 in insulin regulation as well as cholesterol, fatty acid and glucose homeostasis has been linked to obesity, diabetes and cardiovascular disease. As these diseases are all thought to increase risk of $\mathrm{AD}$, this provides further reason to believe that activating Sirt1 by calorie restriction may reduce the risk of AD (Figure 2) [60]. 


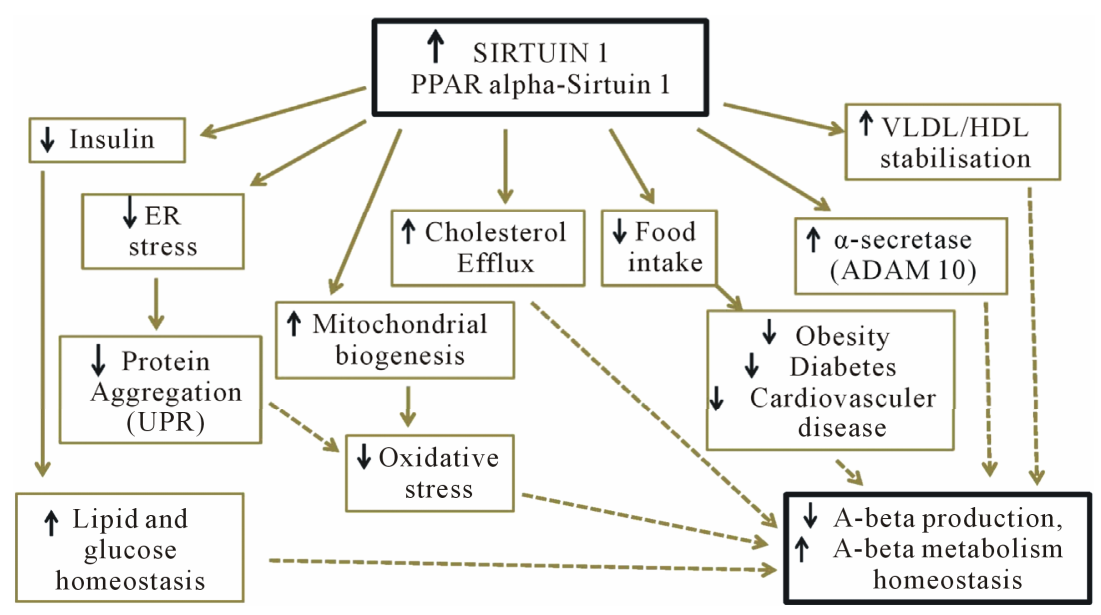

Figure 2. Anti-aging protein Sirtuin 1 controls peripheral cholesterol \& lipid homeostasis and brain amyloid beta metabolism; ER = endoplasmic reticulum, UPR $=$ unfolded protein response, VLDL = very low density lipoprotein, $\mathrm{HDL}=$ high density lipoprotein, PPAR = peroxisome proliferators-activated receptor.

The concept that diet can regulate adipocyte plasma leptin (16 kda protein) as well as Sirt1 levels is supported by reports that high fat diets can lead to leptin resistance and low Sirt1 levels in rats and humans [57,61-64]. Brain Sirt1 expression is increased by caloric restriction and fasting has been shown to increase brain Sirt1 protein content specifically in the hypothalamus. It also appears that the effect of Sirt1 on energy balance is mediated through central melanocortin signalling [58].

Recent studies suggest a functional relevance of SIRT1 in normal brain physiology, neurogenesis and neurological function [42-56]. In one important study for example, Sirt1 was found to downregulate micro-RNA known as miR-134. MiR-134 has been shown to down-regulate cAMP response binding protein (CREB) and brain-derived neurotrophic factor (BDNF), thus reducing synaptic plasticity. Sirt1 can prevent this miR-134-induced downregulation, thereby promoting synaptic plasticity [53]. Since 2005, miRNAs have been linked to complex metabolic processes in mammals, and changes to miRNAs can occur in many metabolic abnormalities and disease conditions. For example obesity, hyperlipidemia (elevated levels of blood lipids), and insulin resistance have been shown to be associated with aberrant expression of multiple essential miRNAs in pancreatic islets of Langerhans and peripheral tissues, including adipose tissue. Furthermore, in obese patients and experimental models of obesity such as 3T3-L1 preadipocytes and adipocytes from leptin deficient mice (ob/ob: mouse model of insulin resistance and obesity) and diet-induced obese mice, miRNAs normally induced during adipogenesis are downregulated. In particular, miR-143, miR-103 and miR-107, known to regulate adipocyte differentiation, are down-regulated in the ob/ob mice, possibly through an inflammatory pathway [65].

\section{SIRTUIN 1 AND THE AMYLOID PRECURSOR PROTEIN (APP) OF ALZHEIMER'S DISEASE}

The maintenance of Sirt1 expression by calorie restriction has the effect of regulating lipid metabolism and energy expenditure, which in turn helps regulate the production of many other proteins $[54,55,57,66]$. In obesity however, Sirt1 levels are reduced and increased plasma Abeta, leptin and body fat have all been shown to correlate with increased adipose tissue size (AT). It has also been shown that Abeta precursor protein (APP) production is upregulated in adipocytes, and that plasma Abeta levels correlate with these increased levels of APP [67]. The increased plasma Abeta is proposed to be due to obesity influencing peripheral Abeta clearance, as obesityin-duced Sirtl dysregulation is strongly associated with liver steatosis and decreased $\mathrm{A} \beta$ clearance by the liver $[15,33,57,66-69]$. Under conditions of calorie restriction on the other hand, $\mathrm{A} \beta$ content in the brain is attenuated, and this effect can be reproduced in mouse neurons in vitro by manipulating cellular SIRT1 expression/activity, ultimately promoting the nonamyloidogenic $\alpha$-secretase processing of the APP, which precludes the generation of Abeta [70]. In particular, the over-expression of SIRT1 in the hippocampus has been shown to provide protection against neurodegeneration in a mouse model of Alzheimer's disease [71], and the over-expression of SIRT1 in the brains of AD-model transgenic mice has been shown to reduce brain Abeta production and amyloid deposition in these mice, due to the induction of the $\alpha$-secretase enzyme ADAM-10 [72]. In the arcuate nucleus of the hypothalamus, there are two types of neurons that play vital roles in regulating feeding and energy expenditure: the anorexigenic proopiomelanocortin (POMC) neurons and 
the orexigenic agouti-related peptide (AgRP) neurons. Sirt1 is expressed in both sets of neurons [51,73].

Alterations in circadian rhythms have been demonstrated in both obesity and $\mathrm{AD}$, and alterations in Sirt1 expression and leptin levels have been associated with this disruption to the daily light/dark cycle. Obese individuals are highly susceptible to circadian desynchrony, especially if on a high fat and cholesterol diet which disrupts normal tissue Sirt1 regulation of cholesterol homeostasis [69,74-76]. PPARgamma, also known for its extensive roles in glucose and lipid metabolism is now emerging as a critical factor in the regulation of circadian networks and it exhibits a circadian expression pattern that is magnified by consumption of a high-fat diet [77]. PPARgamma has been implicated in the pathology of several diseases including obesity, diabetes, atherosclerosis, and cancer, and PPARgamma agonists have been used successfully in the treatment of dyslipidemia and hyperglycemia. In support of Sirtl's role in circadian rhythms, a recent epidemiological study of Sirt1 and circadian locomotor output cycles kaput (CLOCK) genetics found that subjects carrying minor alleles at SIRT1 and CLOCK loci displayed a higher resistance to weight loss compared with homozygotes for both major alleles, suggesting links between the circadian clock and Sirtl function [73].

Other genetic studies are uncovering strong links between obesity and SIRT1 gene polymorphisms. For example, in a Japanese study, the A allele of SIRT1 polymorphism rs7895833, G allele of rs7069102, and T allele of rs2273773 were found to pose a high risk for obesity in men. Furthermore, the A allele of rs 7895833 in women, and the $\mathrm{G}$ allele of rs7069102 and C allele of rs2273773 in men, were found to carry a high risk for hypertension [78]. In later studies by the same group, SIRT1 polymorphisms, rs7069102 and rs2273773, were found to be associated with abnormal cholesterol metabolism and coronary artery calcification, respectively, especially in males [79]. Another recent study of French caucasian adults found a strong association between high BMI and the SIRT1 SNPs rs3395786 and rs11599176, whereas 4 SNPs studied in BMI-discordant siblings of Swedisn families were found to be associated with lower BMI [80]. In another study of the SIRT1 gene, a common SNP in a novel p53-binding sequence in the human SIRT1 promoter was found to affect nutrient-sensitive SIRT1 expression, and thus could have a significant impact on SIRT1mediated changes in human metabolism and physiology that are induced by calorie restriction [81]. In contrast, a German study genotyped 1573 long-lived individuals (centenarians and nonagenarians) and matched younger controls, looking at five SIRT1 single nucleotide polythese polymorphisms on longevity [82]. Such genetic studies are providing a greater understanding of metabolic differences between people and why some individuals may be more susceptible than others to obesity and related metabolic disturbances.

\section{OBESITY, THE ENDOPLASMIC RETICULUM AND ALZHEIMER'S DISEASE}

Common medical conditions that can occur in middle age, such as diabetes, visceral obesity, and atherosclerosis cause considerable stress to the body. Obesity and atherosclerosis are regarded as states of chronic low-grade inflammation. At the cellular level, inflammatory mediators and lipid accumulation can evoke chronic stress, in particular affecting the endoplasmic reticulum (ER). It has recently been shown that the ER responds to metabolic stress through a well-coordinated molecular response. This involves the transcriptional activation of a variety of genes, the attenuation of protein synthesis, the degradation of ER-localised misfolded proteins, and sometimes the onset of apoptosis [83]. Disturbances in liver metabolism are known to be key components in the development of fatty liver, insulin resistance, and atherosclerosis. It has been shown that SIRT1 helps to regulate lipid homeostasis by positively regulating peroxisome proliferators-activated receptor alpha (PPARalpha), a nuclear receptor that mediates the adaptive response to fasting and starvation. This was demonstrated in liver-specific SIRT1 knockout mice, which when challenged with a high fat diet, developed hepatic steatosis, hepatic inflammation, and endoplasmic reticulum stress [46]. In these mice, PPARalpha signalling was shown to be impaired and fatty acid beta-oxidation was decreased. In other studies, the overexpression of SIRT1 in the liver of diet-induced insulin-resistant low-density lipoprotein receptor-deficient mice and of genetically obese ob/ob mice attenuates hepatic steatosis and ameliorates systemic insulin resistance. These beneficial effects were associated with decreased mammalian target of rapamycin complex 1 (mTORC1) activity, inhibited unfolded protein response (UPR) and enhanced insulin receptor signaling in the liver, leading to decreased hepatic gluconeogenesis and improved glucose tolerance. These studies suggest that SIRT1 acts as a negative regulator of UPR signalling in Type II diabetes, and supports the concept that SIRT1 can attenuate hepatic steatosis, reduce insulin resistance, and restore glucose homeostasis, largely through the inhibition of mTORC1 and ER stress [84]. In other recent studies of Sirt1 and diabetes, SIRT1 in HepG2 cells has been shown to regulate ER stress by increasing expression of oxygen-related protein 150 (ORP150), an inducible ER protein thought to be a molecular chaperone involved in $\mathrm{Ca}^{2+}$ metabolism, again supporting the concept that SIRT1 can ameliorate insulin resistance via the regulation of ER stress [85]. 


\section{CONCLUSIONS}

The potential influence of associations between obesity and Alzheimer's disease pathogenesis has been of great interest in recent research. High caloric intake and the consumption of a diet rich in saturated fat have both been associated with obesity, Type II diabetes, cardiovascular disease and Alzheimer's disease. Sirtl appears to play a central role in many metabolic changes that have been implicated in many of these conditions, as well as in AD pathogenesis. Recent studies of Sirt1 and ER function suggest Sirt1 provides considerable protection against metabolic stress via ER regulation.

Several studies have suggested that in early to midadult life, exercise and dietary interventions $[86,87]$ such as calorie restriction may prevent obesity as well as reduce or prevent amyloid deposition in the brain, due to the resultant chronic activation of Sirt1 in tissues such as the brain and the liver. When considering diet, omega -3 fatty acids are important for brain development, and fish consumption has been associated with decreased cognitive deficits and a reduced risk for $\mathrm{AD}[88,89]$. A diet low in saturated fats and cholesterol, yet rich in fruit, vegetables, and omega -3 fatty acids may provide essential micronutrients and antioxidants. Pharmaceutical treatments and/or other therapies centered around Sirt1 regulation might provide promising therapies in the treatment of metabolic diseases including obesity. Studies have already provided support for this theory-for example, the activation of Sirt1 by the polyphenol resveratrol and several synthetic pharmacologic activators has been shown to protect against high-fat diet induced obesity and other metabolic derangements. This is supported by studies which have found that transgenic mice over-expressing SIRT1 are leaner than controls, have a higher metabolism, and have lower serum levels of cholesterol, insulin, and glucose. Thus, calorie restriction, regular exercise, and/or drug treatment in obesity or other disease state may maintain or restore normal SIRT1 gene function. The evidence suggests that this would ultimately stabilise lipid metabolism and cause significant weight loss, reduce obesity and related disorders, as well as reduce or delay the development of Alzheimer's disease.

\section{REFERENCES}

[1] Hansen, J.C., Gilman, A.P. and Odland, J.O. (2010) Is thermogenesis a significant causal factor in preventing the "globesity" epidemic? Medical Hypotheses, 75, 250256. doi:10.1016/j.mehy.2010.02.033

[2] Businaro, R., Ippoliti, F., Ricci, S., Canitano, N. and Fuso, A. (2012) Alzheimer's disease promotion by obesity: Induced mechanisms-molecular links and perspectives. Current Gerontology and Geriatrics Research, 2012, 986823.

[3] Misiak, B., Leszek, J. and Kiejna, A. (2012) Metabolic syndrome, mild cognitive impairment and Alzheimer's disease-The emerging role of systemic low-grade inflammation and adiposity. Brain Research Bulletin, 89, 144-149. doi:10.1016/j.brainresbull.2012.08.003

[4] Luchsinger, J.A. and Mayeux, R. (2007) Adiposity and Alzheimer's disease. Current Alzheimer Research, 4, 127134. doi:10.2174/156720507780362100

[5] Petanceska, S.S. (2007) Exploring the links between obesity and Alzheimer's disease. Current Alzheimer Research, 4, 95-96. doi:10.2174/156720507780362218

[6] Whitmer, R.A. (2007) The epidemiology of adiposity and dementia. Current Alzheimer Research, 4, 117-122. doi: $10.2174 / 156720507780362065$

[7] Wolozin, B. and Bednar, M.M. (2006) Interventions for heart disease and their effects on Alzheimer's disease. Neurology Research, 28, 630-636. doi:10.1179/016164106X130515

[8] Whalley, L.J., Dick, F.D. and McNeill, G. (2006) A lifecourse approach to the aetiology of late-onset dementias. The Lancet Neurology, 5, 87-96. doi:10.1016/S1474-4422(05)70286-6

[9] Weih, M., Wiltfang, J. and Kornhuber, J. (2007) Nonpharmacologic prevention of Alzheimer's disease: Nutritional and life-style risk factors. Journal of Neural Transmission, 114, 1187-1197. doi:10.1007/s00702-007-0704-x

[10] De Mendonca, A.V. (2007) 3rd European symposium on Alzheimer's disease prevention, Lisbonne, June 1st 2007. The Journal of Nutrition Health and Aging, 12, 50S. doi:10.1007/BF02982586

[11] Xu, W.L., Atti, A.R., Gatz, M., Pedersen, N.L., Johansson, B. and Fratiglioni, L. (2011) Midlife overweight and obesity increase late-life dementia risk: A population-based twin study. Neurology, 76, 1568-1574. doi:10.1212/WNL.0b013e3182190d09

[12] Fitzpatrick, A.L., Kuller, L.H., Lopez, O.L., Diehr, P., O'Meara, E.S., Longstreth Jr., W.T., et al. (2009) Midlife and late-life obesity and the risk of dementia: Cardiovascular health study. Archives of Neurology, 66, 336-342. doi:10.1001/archneurol.2008.582

[13] Gustafson, D., Rothenberg, E., Blennow, K., Steen, B. and Skoog, I. (2003) An 18-year follow-up of overweight and risk of Alzheimer disease. Archives of Internal Medicine, 163, 1524-1528. doi:10.1001/archinte.163.13.1524

[14] Kivipelto, M., Ngandu, T., Fratiglioni, L., Viitanen, M., Kareholt, I. Winblad, B., et al. (2005) Obesity and vascular risk factors at midlife and the risk of dementia and Alzheimer disease. Archives of Neurology, 62, 1556-1560. doi:10.1001/archneur.62.10.1556

[15] Balakrishnan, K., Verdile, G., Mehta, P.D., Beilby, J., Nolan, D., Galvao, D.A., et al. (2005) Plasma Abeta42 correlates positively with increased body fat in healthy individuals. Journal of Alzheimer's Disease, 8, 269-282.

[16] Hendrie, H.C., Ogunniyi, A., Hall, K.S., Baiyewu, O.F.W., Unverzagt, O., Gureje, et al., (2001) Incidence of dementia and Alzheimer disease in 2 communities: Yoruba residing in Ibadan, Nigeria, and African Americans residing in Indianapolis, Indiana. JAMA, 285, 739-747. doi:10.1001/jama.285.6.739 
[17] Graves, A.B., Rajaram, L., Bowen, J.D., McCormick, W.C., McCurry, S.M. and Larson, E.B. (1999) Cognitive decline and Japanese culture in a cohort of older Japanese Americans in King County, WA: The Kame Project. The Journals of Gerontology. Series B, Psychological Sciences and Social Sciences, 54, S154-S161. doi:10.1093/geronb/54B.3.S154

[18] Engelhart, M.J., Geerlings, M.I., Ruitenberg, A., Van Swieten, J.C., Hofman, A., Witteman, J.C., et al. (2002) Diet and risk of dementia: Does fat matter: The Rotterdam study. Neurology, 59, 1915-1921. doi:10.1212/01.WNL.0000038345.77753.46

[19] Pasinetti, G.M., Zhao, Z., Qin, W., Ho, L., Shrishailam, Y., Macgrogan, D., et al. (2007) Caloric intake and Alzheimer's disease. Experimental approaches and therapeutic implications. Interdisciplinary Topics in Gerontology, 35, 159-175.

[20] Greenwood, C.E. and Winocur, G. (1990) Learning and memory impairment in rats fed a high saturated fat diet. Behavioral and Neural Biology, 53, 74-87. doi:10.1016/0163-1047(90)90831-P

[21] Martins, I.J. and Redgrave, T.G. (2004) Obesity and postprandial lipid metabolism. Feast or famine? The Journal of Nutritional Biochemistry, 15, 130-141. doi:10.1016/j.jnutbio.2003.10.006

[22] Howard, B.V. (1999) Insulin resistance and lipid metabolism. American Journal of Cardiology, 84, 28J-32J. doi:10.1016/S0002-9149(99)00355-0

[23] Couillard, C., Bergeron, N., Bergeron, J., Pascot, A., Mauriege, P., Tremblay, A., et al. (2000) Metabolic heterogeneity underlying postprandial lipemia among men with low fasting high density lipoprotein cholesterol concentrations. The Journal of Clinical Endocrinology \& Metabolism, 85, 4575-4582. doi:10.1210/jc.85.12.4575

[24] Maesako, M., Uemura, K., Kubota, M., Kuzuya, A., Sasaki, K., Hayashida, N., et al. (2012) Exercise is more effective than diet control in preventing high fat diet-induced beta-amyloid deposition and memory deficit in amyloid precursor protein transgenic mice. The Journal of Biological Chemistry, 287, 23024-23033. doi:10.1074/jbc.M112.367011

[25] Maesako, M., Uemura, K., Kubota, M., Kuzuya, A., Sasaki, K., Asada, M., et al. (2012) Environmental enrichment ameliorated high-fat diet-induced Abeta deposition and memory deficit in APP transgenic mice. Neurobiology of Aging, 33, e11-e23.

[26] Boden, G. (1998) Free Fatty Acids (FFA), a link between obesity and insulin resistance. Frontiers in Bioscience, 3, d169-d175.

[27] Arner, P. (2002) Insulin resistance in type 2 diabetes: Role of fatty acids. Diabetes/Metabolism Research and Reviews, 18, S5-S9. doi:10.1002/dmrr.254

[28] Matsuzawa, Y., Shimomura, I., Nakamura, T., Keno, Y. and Tokunaga, K. (1994) Pathophysiology and pathogenesis of visceral fat obesity. Diabetes Research and Clinical Practice, 24, S111-S116. doi:10.1016/0168-8227(94)90236-4

[29] Das, U.N. (2006) Essential fatty acids: Biochemistry, phy- siology and pathology. Biotechnology Journal, 1, 420-439. doi:10.1002/biot.200600012

[30] Das, U.N. (2006) Essential fatty acids-A review. Current Pharmaceutical Biotechnology, 7, 467-482. doi:10.2174/138920106779116856

[31] Pettegrew, J.W., Panchalingam, K., Hamilton, R.L. and McClure, R.J. (2001) Brain membrane phospholipid alterations in Alzheimer's disease. Neurochemical Research, 26, 771-782. doi:10.1023/A:1011603916962

[32] Prasad, M.R., Lovell, M.A., Yatin, M., Dhillon, H. and Markesbery, W.R. (1998) Regional membrane phospholipid alterations in Alzheimer's disease. Neurochemical Research, 23, 81-88. doi:10.1023/A:1022457605436

[33] Fewlass, D.C., Noboa, K., Pi-Sunyer, F.X., Johnston, J.M., Yan, S.D. and Tezapsidis, N. (2004) Obesity-related leptin regulates Alzheimer's Abeta. FASEB Journal, 18, 1870-1878. doi:10.1096/fj.04-2572com

[34] Considine, R.V., Sinha, M.K., Heiman, M.L., Kriauciunas, A., Stephens, T.W., Nyce, M.R., et al. (1996) Serum immunoreactive-leptin concentrations in normal-weight and obese humans. The New England Journal of Medicine, 334, 292-295. doi:10.1056/NEJM199602013340503

[35] Craft, S. (2007) Insulin resistance and Alzheimer's disease pathogenesis: Potential mechanisms and implications for treatment. Current Alzheimer Research, 4, 147 152. doi:10.2174/156720507780362137

[36] Craft, S. (2005) Insulin resistance syndrome and Alzheimer's disease: Age- and obesity-related effects on memory, amyloid, and inflammation. Neurobiology of Aging, 26, 65-69. doi:10.1016/j.neurobiolaging.2005.08.021

[37] Ho, L., Qin, W., Pompl, P.N., Xiang, Z., Wang, J., Zhao, Z., et al. (2004) Diet-induced insulin resistance promotes amyloidosis in a transgenic mouse model of Alzheimer's disease. FASEB Journal, 18, 902-904.

[38] Zhao, Z., Xiang, Z., Haroutunian, V., Buxbaum, J.D., Stetka, B. and Pasinetti, G.M. (2007) Insulin degrading enzyme activity selectively decreases in the hippocampal formation of cases at high risk to develop Alzheimer's disease. Neurobiology of Aging, 28, 824-830. doi:10.1016/j.neurobiolaging.2006.05.001

[39] Clandinin, M.T., Cheema, S., Field, C.J. and Baracos, V.E. (1993) Dietary lipids influence insulin action. Annals of the New York Academy of Sciences, 683, 151-163. doi:10.1111/j.1749-6632.1993.tb35701.x

[40] Storlien, L.H., Kriketos, A.D., Jenkins, A.B., Baur, L.A., Pan, D.A., Tapsell, L.C., et al. Does dietary fat influence insulin action? Annals of the New York Academy of Sciences, 827, 287-301. doi:10.1111/j.1749-6632.1997.tb51842.x

[41] Manco, M., Bertuzzi, A., Salinari, S., Scarfone, A., Calvani, M., Greco, A.V., et al. (2004) The ingestion of saturated fatty acid triacylglycerols acutely affects insulin secretion and insulin sensitivity in human subjects. British Journal of Nutrition, 92, 895-903. doi:10.1079/BJN20041268

[42] Hsu, C.P., Odewale, I., Alcendor, R.R. and Sadoshima, J. (2008) Sirtl protects the heart from aging and stress. Biological chemistry, 389, 221-231. 
doi:10.1515/BC.2008.032

[43] Borradaile, N.M. and Pickering, J.G. (2009) NAD(+), sirtuins, and cardiovascular disease. Current pharmaceutical design, 15, 110-117.

[44] Stein, S. and Matter, C.M. (2011) Protective roles of SIRT1 in atherosclerosis. Cell Cycle, 10, 640-647. doi:10.4161/cc.10.4.14863

[45] Shi, Y., Camici, G.G. and Luscher, T.F. (2010) Cardiovascular determinants of life span. European Journal of Physiology, 459, 315-324.

[46] Purushotham, A., Schug, T.T., Xu, Q., Surapureddi, S., Guo, X. and Li, X. (2009) Hepatocyte-specific deletion of SIRT1 alters fatty acid metabolism and results in hepatic steatosis and inflammation. Cell Metabolism, 9, 327-338. doi:10.1016/j.cmet.2009.02.006

[47] Elliott, P.J. and Jirousek, M. (2008) Sirtuins: Novel targets for metabolic disease. Current Opinion in Investigational Drugs, 9, 371-378.

[48] Colak, Y., Ozturk, O., Senates, E., Tuncer, I., Yorulmaz, E., Adali, G., et al. (2011) SIRT1 as a potential therapeutic target for treatment of nonalcoholic fatty liver disease. International Medical Journal of Experimental and Clinical Research, 17, HY5-9.

[49] Zhang, Z., Lowry, S.F., Guarente, L. and Haimovich, B. (2010) Roles of SIRT1 in the acute and restorative phases following induction of inflammation. The Journal of Biological Chemistry, 285, 41391-41401. doi:10.1074/jbc.M110.174482

[50] Yoshizaki, T., Milne, J.C., Imamura, T., Schenk, S., Sonoda, N., Babendure, J.L., et al., SIRT1 exerts anti-inflammatory effects and improves insulin sensitivity in adipocytes. Molecular and Cellular Biology, 29, 1363-1374. doi:10.1128/MCB.00705-08

[51] Sasaki, T. and Kitamura, T. (2010) Roles of FoxO1 and Sirt1 in the central regulation of food intake. Endocrine Journal, 57, 939-946. doi:10.1507/endocrj.K10E-320

[52] Michan, S., Li, Y., Chou, M.M., Parrella, E., Ge, H., Long, J.M., et al. (2010) SIRT1 is essential for normal cognitive function and synaptic plasticity. The Journal of Neuroscience, 30, 9695-9707.

[53] Gao, J., Wang, W.Y., Mao, Y.W., Graff, J., Guan, J.S., Pan, L., et al. (2010) A novel pathway regulates memory and plasticity via SIRT1 and miR-134. Nature, 466, 1105-1109. doi:10.1038/nature09271

[54] Guarente, L. (2008) Mitochondria-A nexus for aging, calorie restriction, and sirtuins? Cell, 132, 171-176. doi:10.1016/j.cell.2008.01.007

[55] Libert, S., Cohen, D. and Guarente, L. (2008) Neurogenesis directed by Sirt1. Nature Cell Biology, 10, 373-374. doi:10.1038/ncb0408-373

[56] Silva, J.P. and Wahlestedt, C. (2010) Role of Sirtuin 1 in metabolic regulation. Drug Discovery Today, 15, 781-791. doi:10.1016/j.drudis.2010.07.001

[57] Schug, T.T. and Li, X. (2011) Sirtuin 1 in lipid metabolism and obesity. Annals of Medicine, 43, 198-211. doi:10.3109/07853890.2010.547211

[58] Cakir, I., Perello, M., Lansari, O., Messier, N.J., Vaslet,
C.A. and Nillni, E.A. (2009) Hypothalamic Sirt1 regulates food intake in a rodent model system. PLoS One, 4, e8322. doi:10.1371/journal.pone.0008322

[59] Guarente, L. (2007) Sirtuins in aging and disease. Cold Spring Harbor Symposia on Quantitative Biology, 72, 483-488. doi:10.1101/sqb.2007.72.024

[60] Qin, W., Yang, T., Ho, L., Zhao, Z., Wang, J., Chen, L., et al. (2006) Neuronal SIRT1 activation as a novel mechanism underlying the prevention of Alzheimer disease amyloid neuropathology by calorie restriction. The Journal of Biological Chemistry, 281, 21745-21754. doi:10.1074/jbc.M602909200

[61] Pfluger, P.T., Herranz, D., Velasco-Miguel, S., Serrano, M. and Tschop, M.H. (2008) Sirt1 protects against high-fat diet-induced metabolic damage. Proceedings of the $\mathrm{Na}$ tional Academy of Sciences of the United States of America, 105, 9793-9798. doi:10.1073/pnas.0802917105

[62] Deng, X.Q., Chen, L.L. and Li, N.X. (2007) The expression of SIRT1 in nonalcoholic fatty liver disease induced by high-fat diet in rats. Official Journal of the International Association for the Study of the Liver, 27, 708-715.

[63] Havel, P.J., Townsend, R., Chaump, L. and Teff, K. (1999) High-fat meals reduce 24-h circulating leptin concentrations in women. Diabetes, 48, 334-341. doi: $10.2337 /$ diabetes.48.2.334

[64] Lomb, D.J., Laurent, G. and Haigis, M.C. (2010) Sirtuins regulate key aspects of lipid metabolism. Biochimica et Biophysica Acta, 1804, 1652-1657. doi:10.1016/j.bbapap.2009.11.021

[65] Xie, H., Lim, B. and Lodish, H.F. (2009) MicroRNAs induced during adipogenesis that accelerate fat cell development are downregulated in obesity. Diabetes, 58, 1050-1057. doi: $10.2337 / \mathrm{db08-1299}$

[66] Lee, Y.H., W.G. Tharp, R.L. Maple, S. Nair, P.A. Permana, and Pratley, R.E. (2008) Amyloid precursor protein expression is upregulated in adipocytes in obesity. Obesity, 16, 1493-1500. doi:10.1038/oby.2008.267

[67] Lee, Y.H., Martin, J.M., Maple, R.L., Tharp, W.G. and Pratley, R.E. (2009) Plasma amyloid-beta peptide levels correlate with adipocyte amyloid precursor protein gene expression in obese individuals. Neuroendocrinology, 90, 383-390. doi:10.1159/000235555

[68] Leahey, T.M., Myers, T.A., Gunstad, J., Glickman, E., Spitznagel, M.B., Alexander, T., et al. (2007) Abeta40 is associated with cognitive function, body fat and physical fitness in healthy older adults. Nutritional Neuroscience, 10, 205-209. doi:10.1080/10284150701676156

[69] Holden, K.F., Lindquist, K., Tylavsky, F.A., Rosano, C., Harris, T.B. and Yaffe, K. (2009) Serum leptin level and cognition in the elderly: Findings from the health $\mathrm{ABC}$ study. Neurobiology of Aging, 30, 1483-1489. doi:10.1016/j.neurobiolaging.2007.11.024

[70] Gan, L. (2007) Therapeutic potential of sirtuin-activating compounds in Alzheimer's disease. Drug News \& Perspectives, 20, 233-239. doi:10.1358/dnp.2007.20.4.1101162

[71] Kim, D., Nguyen, M.D., Dobbin, M.M., Fischer, A., Sananbenesi, F., Rodgers, J.T., et al. (2007) SIRT1 deacety- 
lase protects against neurodegeneration in models for Alzheimer's disease and amyotrophic lateral sclerosis. EMBO Journal, 26, 3169-3179. doi:10.1038/sj.emboj.7601758

[72] Donmez, G., Wang, D., Cohen, D.E. and Guarente, L. (2010) SIRT1 suppresses beta-amyloid production by activating the alpha-secretase gene ADAM10. Cell, 142, 320-332. doi:10.1016/j.cell.2010.06.020

[73] Garaulet, M., Esteban Tardido, A., Lee, Y.C., Smith, C.E., Parnell, L.D. and Ordovas, J.M. (2012) SIRT1 and CLOCK $3111 \mathrm{~T}>\mathrm{C}$ combined genotype is associated with evening preference and weight loss resistance in a behavioral therapy treatment for obesity. International Journal of Obesity.

[74] Feige, J.N. and Auwerx, J. (2007) DisSIRTing on LXR and cholesterol metabolism. Cell Metabolism, 6, 343-345. doi:10.1016/j.cmet.2007.10.003

[75] Li, X., Zhang, S., Blander, G., Tse, J.G., Krieger, M. and Guarente, L. (2007) SIRT1 deacetylates and positively regulates the nuclear receptor LXR. Molecular Cell, 28, 91-106. doi:10.1016/j.molcel.2007.07.032

[76] Cao, G., Bales, K.R., DeMattos, R.B. and Paul, S.M. (2007) Liver X receptor-mediated gene regulation and cholesterol homeostasis in brain: Relevance to Alzheimer's disease therapeutics. Current Alzheimer Research, 4, 179-184. doi:10.2174/156720507780362173

[77] Kawai, M. and Rosen, C.J. (2010) PPARgamma: A circadian transcription factor in adipogenesis and osteogenesis. Nature Reviews Endocrinology, 6, 629-636. doi:10.1038/nrendo.2010.155

[78] Shimoyama, Y., Suzuki, K., Hamajima, N. and Niwa, T. (2011) Sirtuin 1 gene polymorphisms are associated with body fat and blood pressure in Japanese. Translational Research, 157, 339-347. doi:10.1016/j.trs1.2011.02.004

[79] Shimoyama, Y., Mitsuda, Y., Tsuruta, Y., Suzuki, K., Hamajima, N. and Niwa, T. (2012) SIRTUIN 1 gene polymorphisms are associated with cholesterol metabolism and coronary artery calcification in Japanese hemodialysis patients. Journal of Renal Nutrition, 22, 114-119. doi:10.1053/j.jrn.2011.10.025

[80] Clark, S.J., Falchi, M., Olsson, B., Jacobson, P., Cauchi, S., Balkau, B., et al. (2012) Association of sirtuin 1 (SIRT1) gene SNPs and transcript expression levels with severe obesity. Obesity (Silver Spring), 20, 178-185. doi:10.1038/oby.2011.200

[81] Naqvi, A., Hoffman, T.A., DeRicco, J., Kumar, A., Kim, C.S., Jung, S.B., et al. (2010) A single-nucleotide variation in a p53-binding site affects nutrient-sensitive human SIRT1 expression. Human Molecular Genetics, 19, 41234133. doi:10.1093/hmg/ddq331

[82] Flachsbart, F., Croucher, P.J., Nikolaus, S., Hampe, J., Cordes, C., Schreiber, S., et al. (2006) Sirtuin 1 (SIRT1) sequence variation is not associated with exceptional human longevity. Experimental Gerontology, 41, 98-102. doi:10.1016/j.exger.2005.09.008

[83] Tsiotra, P.C. and Tsigos, C. (2006) Stress, the endoplasmic reticulum, and insulin resistance. Annals of the New York Academy of Sciences, 1083, 63-76. doi:10.1196/annals.1367.007

[84] Li, Y., Xu, S., Giles, A., Nakamura, K., Lee, J.W., Hou, X., et al. (2011) Hepatic overexpression of SIRT1 in mice attenuates endoplasmic reticulum stress and insulin resistance in the liver. FASEB Journal, 25, 1664-1679. doi:10.1096/fj.10-173492

[85] Jung, T.W., Lee, K.T., Lee, M.W. and Ka, K.H. (2012) SIRT1 attenuates palmitate-induced endoplasmic reticulum stress and insulin resistance in HepG2 cells via induction of oxygen-regulated protein 150. Biochemical and Biophysical Research Communications, 422, 229-232. doi:10.1016/j.bbrc.2012.04.129

[86] Marton, O., Koltai, E., Nyakas, C., Bakonyi, T., Zenteno-Savin, T., Kumagai, S., et al. (2010) Aging and exercise affect the level of protein acetylation and SIRT1 activity in cerebellum of male rats. Biogerontology, 11 679-686. doi:10.1007/s10522-010-9279-2

[87] Ferrara, N., Rinaldi, B., Corbi, G., Conti, V., Stiuso, P., Boccuti, S., et al. (2008) Exercise training promotes SIRT1 activity in aged rats. Rejuvenation Research, 11, 139-150. doi:10.1089/rej.2007.0576

[88] Grant, W.B., Campbell, A., Itzhaki, R.F. and Savory, J. (2002) The significance of environmental factors in the etiology of Alzheimer's disease. Journal of Alzheimers Disease, 4, 79-189.

[89] Solfrizzi, V., Panza, F. and Capurso, A. (2003) The role of diet in cognitive decline. Journal of Neural Transmission, 110, 95-110. 